\title{
Periodic Change in the Ni Content in a Co-Ni Thin Film Electrodeposited Using a Rectangular Pulse Current over a Megahertz Frequency Range
}

\author{
M. Saitou \\ University of the Ryukyus, Department of Mechanical Systems Engineering, 1 Senbaru Nishihara-cho \\ Okinawa, 903-0213, Japan. \\ E-mail: saitou@tec.u-ryukyu.ac.jp
}

doi: $10.20964 / 2018.01 .05$

Received: 21 September 2017 / Accepted: 19 October 2017 / Online Published: 1 December 2017

\begin{abstract}
Co-Ni thin films electrodeposited using a rectangular pulse current over a megahertz frequency range were investigated. Energy dispersive X-ray spectroscopy identified a resonant frequency at which the $\mathrm{Ni}$ content in the Co-Ni thin film had a maximal value. A periodic change in the $\mathrm{Ni}$ content in the Co$\mathrm{Ni}$ thin film emerged at a constant resonant frequency interval of $0.1 \mathrm{MHz}$ between the neighboring resonant frequencies. X-ray diffraction analysis showed that a Co-Ni thin film containing more than 33 $\mathrm{wt} \% \mathrm{Ni}$ had a face-centered cubic (FCC) crystal structure, and that containing less than $28 \mathrm{wt} \%$ had a hexagonal close-packed (HCP) crystal structure. This indicated that the phase transition between the FCC and HCP structures occurred at the critical Ni content. The periodic change in the Ni content in the Co-Ni thin film was explained by an energy level transition of electrons that caused a resonant generation of $\mathrm{Co}$ and $\mathrm{Ni}$.
\end{abstract}

Keywords: Co-Ni thin film; Energy level transition; Resonant frequency; Resonant frequency interval; Phase transition; FCC; HCP

\section{$\underline{\text { FULL TEXT }}$}

(C) 2018 The Authors. Published by ESG (www.electrochemsci.org). This article is an open access article distributed under the terms and conditions of the Creative Commons Attribution license (http://creativecommons.org/licenses/by/4.0/). 